Case Report

\title{
A Giant Ureteral Stone without Underlying Anatomic or Metabolic Abnormalities: A Case Report
}

\author{
Selcuk Sarikaya, Berkan Resorlu, Ekrem Ozyuvali, Omer Faruk Bozkurt, \\ Ural Oguz, and Ali Unsal
}

Department of Urology, Kecioren Training and Research Hospital, Kecioren, 06380 Ankara, Turkey

Correspondence should be addressed to Berkan Resorlu; drberkan79@gmail.com

Received 6 June 2013; Accepted 10 October 2013

Academic Editor: Thomas J. Vogl

Copyright (c) 2013 Selcuk Sarikaya et al. This is an open access article distributed under the Creative Commons Attribution License, which permits unrestricted use, distribution, and reproduction in any medium, provided the original work is properly cited.

\begin{abstract}
A 28-year old man presented with left flank pain and dysuria. Plain abdominal film and computed tomography showed a left giant ureteral stone measuring $11.5 \mathrm{~cm}$ causing ureteral obstruction and other stones $2.5 \mathrm{~cm}$ in size in the lower pole of ipsilateral kidney and $7 \mathrm{~mm}$ in size in distal part of right ureter. A left ureterolithotomy was performed and then a double J stent was inserted into the ureter. The patient was discharged from the hospital 4 days postoperatively with no complications. Stone analysis was consistent with magnesium ammonium phosphate and calcium oxalate. Underlying anatomic or metabolic abnormalities were not detected. One month after surgery, right ureteral stone passed spontaneously, left renal stone moved to distal ureter, and it was removed by ureterolithotomy. Control intravenous urography and cystography demonstrated unobstructed bilateral ureter and the absence of vesicoureteral reflux.
\end{abstract}

\section{Introduction}

Stones may be located in different anatomical locations of urinary tract; however, ureteral stones are usually located in three anatomic stenotic sites of ureter $[1,2]$. Stone size, in particular the maximum diameter, is the most important factor dictating how a stone should be managed [2-4]. In general, ureteral stones larger than $10 \mathrm{~mm}$ in diameter are less likely to be passed and the majority of these patients require intervention [5]. Extracorporeal shock wave lithotripsy (SWL) and ureteroscopy (URS) are the main treatment modalities for these stones [6]. However some ureteral calculi show silent progression to reach a large size and can be larger than $10 \mathrm{~cm}$ in length or weighing more than 50 gram. These stones are called giant ureteral stones and seen extremely rare $[5,7]$. In this study we report a case of giant ureteral calculi with ipsilateral renal calculi and contralateral distal ureteral calculi without underlying metabolic or anatomic abnormalities, which to our knowledge has not been reported before.

\section{Case Report}

A 28-year-old man presented with bilateral flank pain and dysuria. Urinalysis revealed microscopic hematuria and pyuria. Urine culture was positive for Proteus mirabilis and was treated with ceftriaxone $1 \mathrm{~g}$ twice a day for 5 days. The urine culture became negative before the operation. Serum creatinine level was $1.9 \mathrm{mg} / \mathrm{dL}$ and other laboratory studies revealed no significant abnormalities. Physical examination did not yield anything apart from tenderness in left costovertebral angle location. Ultrasound (US) detected hydronephrosis and hydroureter on the left side. A plain abdominal film (KUB) and computed tomography (CT) showed a left giant ureteral stone measuring $11.5 \mathrm{~cm}$ causing ureteral obstruction and other stones $2.5 \mathrm{~cm}$ in size in the lower pole of ipsilateral kidney and $7 \mathrm{~mm}$ in size in distal part of right ureter (Figure 1).

A left ureterolithotomy operation was performed and stone was removed through a longitudinal incision (Figure 2). The ureteral wall was thick and chronically inflamed. Therefore a double J stent was inserted into the ureter and incision was closed. The stone was measured $11.5 \mathrm{~cm}$ in length and composed of magnesium ammonium phosphate (75\%) and calcium oxalate $(25 \%)$. The patient was discharged from the hospital on postoperative day 4 without any complication. The double J stent was removed under brief anesthesia 14 days postoperatively. 

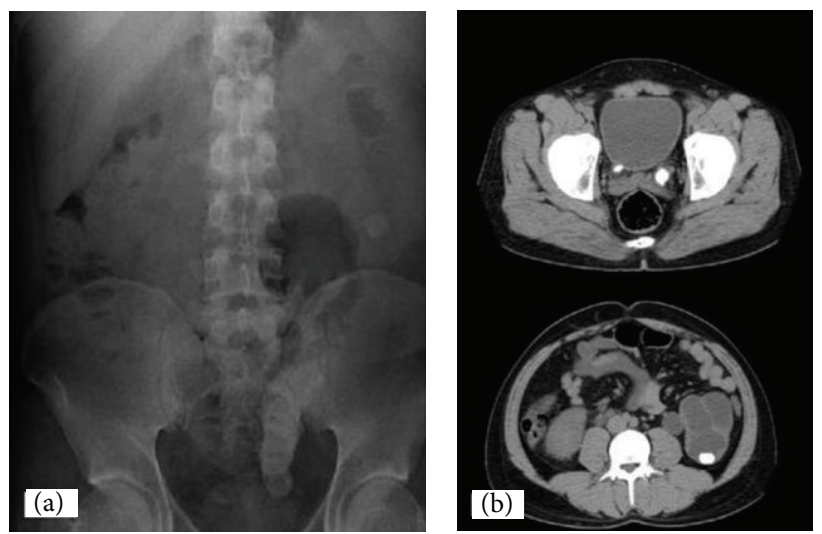

Figure 1: Plain film shows a long radiopaque density $(11.5 \mathrm{~cm}$ ) suggesting a giant ureteral stone in the pelvic area (a). The CT scan of the abdomen shows a left giant ureteral stone measuring $11.5 \mathrm{~cm}$ causing ureteral obstruction and other stones $2.5 \mathrm{~cm}$ in size in the lower pole of ipsilateral kidney and $7 \mathrm{~mm}$ in size in distal part of right ureter (b).
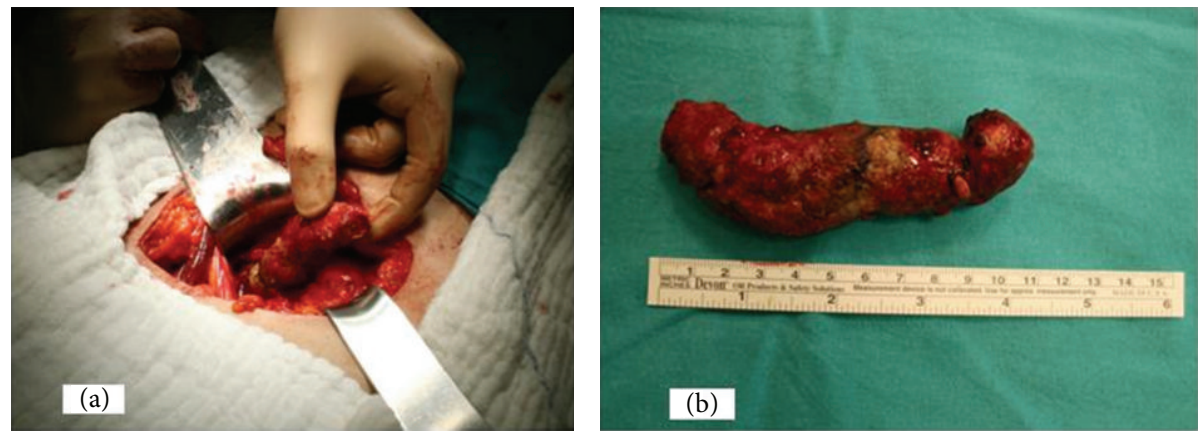

FIGURE 2: Ureterolithotomy operation (a) and removed giant ureteral stone (b).

One month after surgery, right ureteral stone passed spontaneously. For the management of left renal stone we planned to perform percutaneous nephrolithotomy; however, on the follow-up period this stone moved to distal ureter. So it was removed by ureterolithotomy again. Control intravenous urography and cystography demonstrated unobstructed bilateral ureter and the absence of vesicoureteral reflux. A primary metabolic evaluation was performed including urine $\mathrm{pH}$, serum calcium, phosphorus, uric acid, and 24-hour urinary calcium, phosphorus, oxalate, citrate, uric acid, creatinine, and electrolytes. We did not find any significant abnormalities in this evaluation.

\section{Discussion}

Stone size and location are the most important factors used to predict the likelihood of spontaneous passage in patients with ureteral stones [2-4]. The American Urological Association (AUA) guidelines, which are based on a meta-analysis of the literature, indicate that up to $98 \%$ of ureteral calculus $4 \mathrm{~mm}$ or smaller will pass spontaneously [8]. Furthermore frequency of spontaneous passage of stones in the mid and distal ureter was significantly higher than that of stones in the proximal ureter [9].

Large ureteral stones frequently cause pain and infection because of stone impaction and pelvicaliceal system obstruction [10]. This condition may result in partial or even complete loss of the renal functions if the treatment is not done promptly [11]. Currently SWL and URS are the most widely used noninvasive treatment modalities for ureteral stones. However, these minimally invasive techniques are not usable for complex large stones [6]. The management of large ureteral calculus depends on the function of the affected kidney and can require nephroureterectomy or the removal of the stones [12].

Giant ureteral stones (more than $10 \mathrm{~cm}$ in length or 50 gram in weight) are extremely rare in the literature. In 1992, Sabnis et al. reported the largest ureteric stone in the literature measuring $13 \mathrm{~cm}$ in length and weighing 90 gram [7]. However the etiology and pathology of these stones remain unclear. Some authors have reported giant ureteral stones in association with ureteral duplication, ureteroceles, tuberculosis, megaureter, or prolapsed benign polyp of the ureter [12-15]. Therefore a urinary tract abnormality or a metabolic defect may play an important role in the pathogenesis of these stones. But in our case we could not find any anatomic or metabolic abnormalities.

\section{References}

[1] C. Kara, M. Bayindir, O. F. Bozkurt et al., "Giant ureteral stone: case report," The New Journal of Urology, vol. 4, pp. 45-48, 2008. 
[2] H. W. Kim, K. D. Kim, Y. T. Moon, and S. C. Kim, "A giant ureteral stone," Journal of Korean Medical Science, vol. 10, no. 1, pp. 48-50, 1995.

[3] B. Resorlu, C. Kara, E. B. Resorlu, and A. Unsal, "Effectiveness of ultrasonography in the postoperative follow-up of pediatric patients undergoing ureteroscopic stone manipulation," Pediatric Surgery International, vol. 27, no. 12, pp. 1337-1341, 2011.

[4] A. Rauf and H. Rauf, "Giant ureteric stone: case report," Nishtar Medical Journal, vol. 2, pp. 64-66, 2010.

[5] Y. B. Jeong, J. K. Park, H. J. Kim, Y. G. Kim, and M. K. Kim, "Giant ureteral stone in a patient with a single functioning kidney: a case report," Clinical Nephrology, vol. 75, no. 6, pp. 547-549, 2011.

[6] C. Türk, T. Knoll, A. Petrik, K. Sarica, M. Straub, and C. Seitz, "Guidelines on Urolithiasis," 2012, 1-102, http://www.uroweb .org/gls/pdf/20_Urolithiasis_LR\%20March\%2013\%202012.pdf.

[7] R. B. Sabnis, R. M. Desai, A. M. Bradoo, S. V. Punekar, and S. D. Bapat, "Giant ureteral stone," Journal of Urology, vol. 148, no. 3, pp. 861-862, 1992.

[8] C. F. Wu, J. J. Shee, W. Y. Lin, C. L. Lin, and C. S. Chen, "Comparison between extracorporeal shock wave lithotripsy and semirigid ureterorenoscope with holmium:YAG laser lithotripsy for treating large proximal ureteral stones," Journal of Urology, vol. 172, no. 5, pp. 1899-1902, 2004.

[9] J. W. Segura, G. M. Preminger, D. G. Assimos et al., "Ureteral stones clinical guidelines panel summary report on the management of ureteral calculi," Journal of Urology, vol. 158, no. 5, pp. 1915-1921, 1997.

[10] D. M. Coll, M. J. Varanelli, and R. C. Smith, "Relationship of spontaneous passage of ureteral calculi to stone size and location as revealed by unenhanced helical CT," American Journal of Roentgenology, vol. 178, no. 1, pp. 101-103, 2002.

[11] M. C. Cheung, F. Lee, S. K. H. Yip, and P. C. Tam, "Outpatient holmium laser lithotripsy using semirigid ureteroscope: is the treatment outcome affected by stone load?" European Urology, vol. 39, no. 6, pp. 702-708, 2001.

[12] A. B. Pintér, M. Andits, and F. Szemlédy, "Giant ureteral stone in a 4-year-old boy," Pediatric Surgery International, vol. 13, no. 2-3, pp. 202-203, 1998.

[13] M. Eroglu, A. Unsal, E. Cimentepe, and H. Bakirtas, "Giant ureteral stone associated with partial ureteral duplication," International Urology and Nephrology, vol. 35, no. 4, pp. 485487, 2003.

[14] A. Metin, O. Bulut, O. Atahan, and O. Kayigil, "Giant ureteral calculus due to tuberculosis," International Urology and Nephrology, vol. 25, no. 6, pp. 543-545, 1993.

[15] A. Terai, T. Terachi, and S. Yoshida, "Prolapsed benign polyp of ureter associated with giant ureteral calculus," Acta Urologica Japonica, vol. 35, no. 5, pp. 871-873, 1989. 


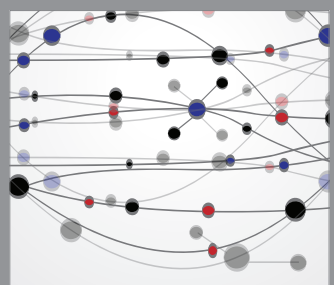

The Scientific World Journal
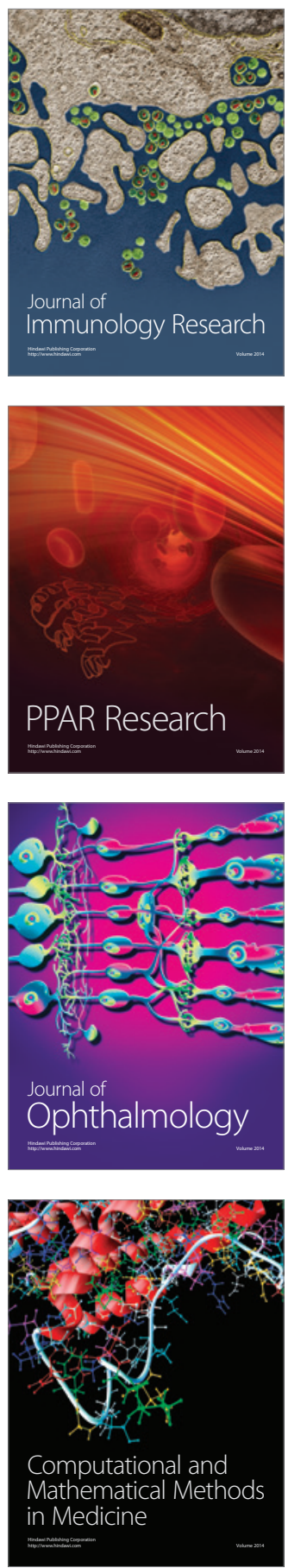

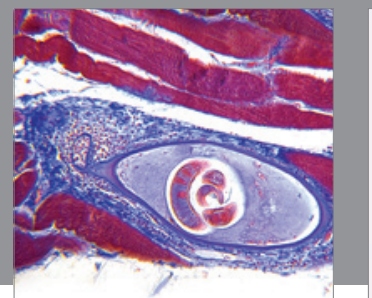

Gastroenterology

Research and Practice
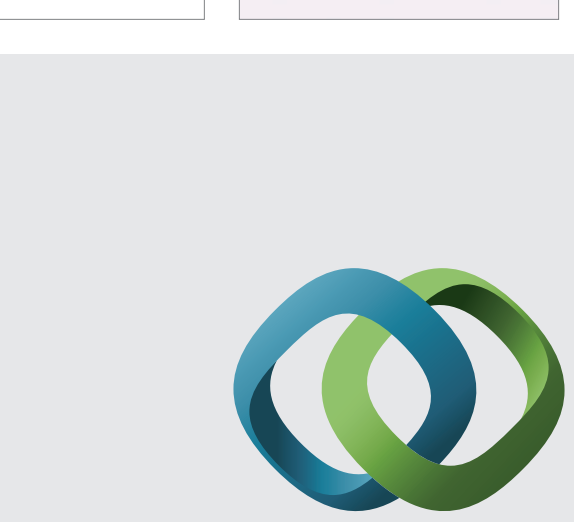

\section{Hindawi}

Submit your manuscripts at

http://www.hindawi.com
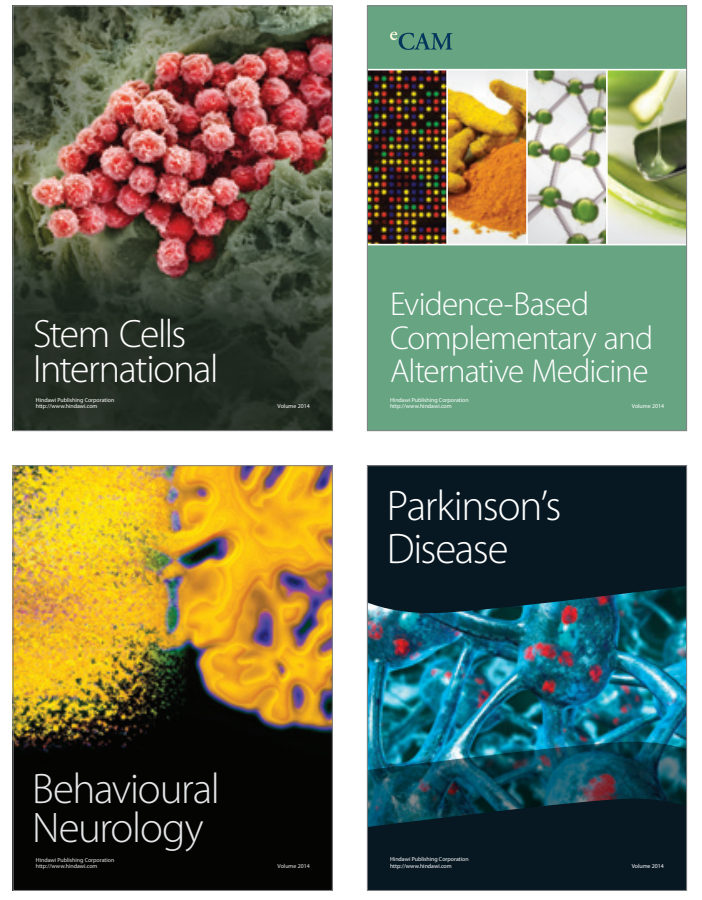
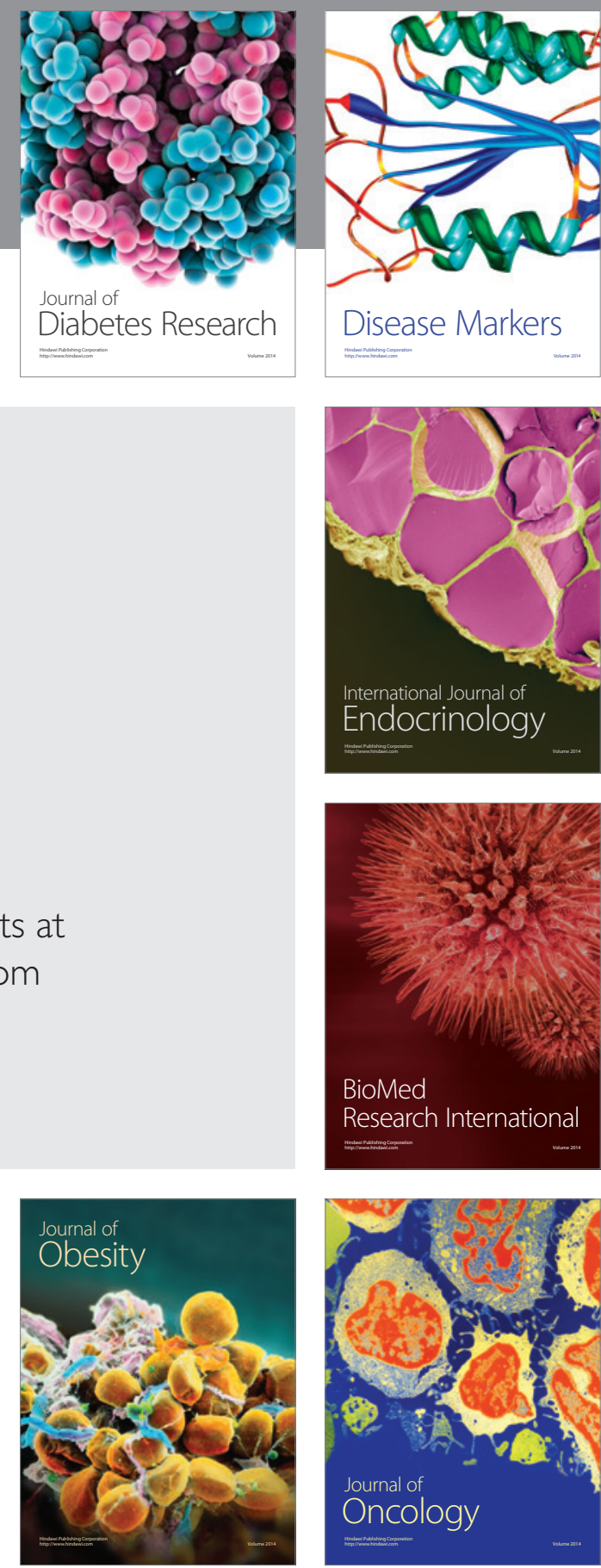

Disease Markers
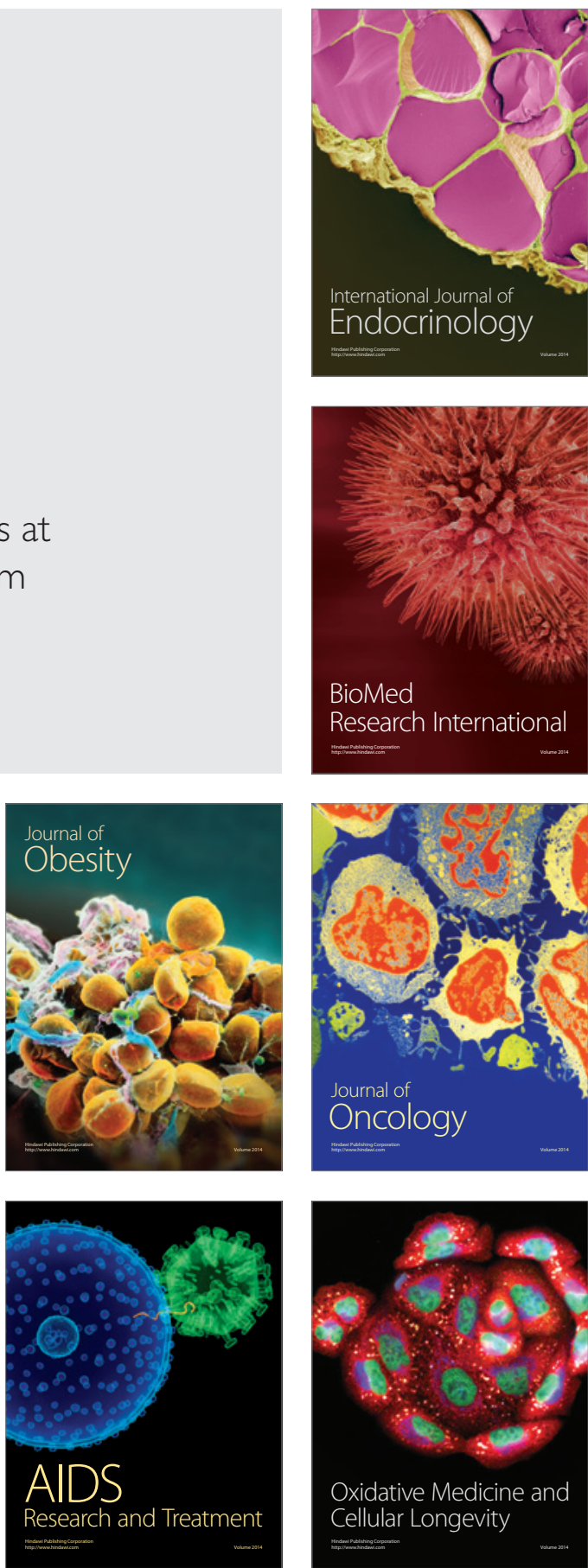